\title{
Identity Construction through Code-Switching Practices at a University in Pakistan
}

\author{
Mujahid Shah ${ }^{a}$ \\ mujahidshah@awkum.edu.pk \\ Faculty of Arts \& Humanities, \\ Abdul Wali Khan University, Pakistan \\ Stefanie Pillai \\ stefanie@um.edu.my \\ Faculty of Languages \& Linguistics, \\ Universiti Malaya, Malaysia \\ Malarvizhi Sinayah ${ }^{b}$ \\ malarvizhisinayah@um.edu.my \\ Faculty of Languages \& Linguistics, \\ Universiti Malaya, Malaysia
}

\begin{abstract}
Code-switching can be used to express and create different meanings and ideologies, as well as different identities. Speakers can choose various codes in their linguistic repertoires to do these things. In academic settings in Pakistan, English is likely to be used with Urdu and regional languages, such as Pashto, resulting in the expression and construction of different identities. In order to examine the link between code-switching and identity in a multilingual academic setting, this paper examines the construction of identity that emerges from codeswitching practices among a group of lecturers and students at a university in Pakistan. Data were collected through recordings of interactions supplemented with semi-structured interviews, which were then ethnographically analysed from a micro-macro perspective. The findings revealed a seamless and dynamic use of code-switching, which was mainly in English and Pashto. The fluid nature of the code-switching makes it seem as if speakers have developed a different 'language' combining Pashto and English. Such use of code-switching reflects their socialisation in a multilingual and multicultural environment, which in turn, has led to the emergence of their hybrid identity orientations. The study contributes empirical evidence of the link between code-switching and hybrid identities in a multilingual context. The findings also imply that interactive practices should be examined from a dynamic micro-macro perspective because changes in the social environment can affect the thinking, perceptions, behaviours, and identity-orientations of the speakers.
\end{abstract}

Keywords: code-switching; hybrid identity; Pakistan; Pashto; academic setting

\section{INTRODUCTION}

The socio-cultural, socio-political and historical backgrounds of speakers are closely related to the negotiation between "Self" and the "Other" (Bucholtz \& Hall, 2005, p. 586). In this vein, code-switching (CS) is not just the mixing or alternation of linguistic codes, but is a source of creation and recreation of different meanings, ideologies, social and ethnic identities. In view of this, identity can be defined as the perception of a person about themselves in relation to the

\footnotetext{
${ }^{a}$ Main author

${ }^{b}$ Corresponding author
} 
world around them. It also refers to specific attributes which determine the relation of an individual with his surroundings (Norton, 2000). The link between identity and CS in this context is rooted in the socio-cultural context of the community concerned. Consequently, changes in the concept of identity can be attributed to changes in the social environment.

Some studies have represented this socio-cultural impact on languages in a static way, and labelled language choices and selections as a reflection of the social environment. Studies applying such a macro sociolinguistic approach assume a prior symbolic relation between particular ideas or concepts and language structures. The assumption here is that social factors, such as class, gender, ethnicity, language policy, and national and global ideologies, govern and guide the interactive behaviours and practices of the speaker. These macro forces are seen as being reflective of the interactive practices and behaviours of speakers (Chang, 2014; Debose, 1992; Smirnova \& Iliev, 2016). For example, Chang (2014) investigated CS in the interactive practices of the students in the context of Pangcah and Mandarin at the school level in Taiwan. The study showed that Mandarin, being the medium of instruction, was assumed as a representation of hegemonic domination. On the other hand, Pangcah, which is the native language of the speakers, was associated with a lower social status. Thus, the choice between Pangcah and Mandarin was seen as a choice between allegiance to the state, or to speakers' social heritage. In this way, a direct correlation between Pangcah with ethnic attachment, and Mandarin with state policy was established. In addition, each language was used in relation to a power paradigm, where the speakers and their interactive practices represented were assumed as symbols reflecting power.

The present study examines another multilingual context, this time in Pakistan, to see how a group of speakers negotiates between a local (Pashto) and global (English) language through their CS practices. There are about 77 languages spoken in different regions of Pakistan. English is the official language used as medium of instruction in higher education, while the national language, Urdu, generally acts as lingua franca (Manan, David, Dumanig \& Channa, 2017; Shah, Pillai \& Sinayah, 2019). English has occupied a dominant position in Pakistan and is used not only in higher education but in the judiciary, media, civil services, and administration (Manan, Dumanig \& David, 2017). Soon after the occupation of United India, the British entrenched the English language in the educational, administrative and legal set up of the region in such a way that the people had no other choice but to learn English for their socio-economic survival and social mobility (Mahboob, 2017). After independence in 1947, Pakistan continued with the same system wherein English remained in place and occupied the same position (official language and medium of instruction). Competitive examinations for the civil service and other lucrative and prestigious positions continued to be held in English. In this way, English exists with other regional languages such as Pashto, and this has impacted local culture and the identities of the speakers (Shah, Pillai \& Sinayah, 2019). Consequently, this situation led to the development of speakers' hybrid orientations. In relation to this, an investigation of how the lecturers and students negotiate local and global identities in their CS practices in a Pakistani university could provide new insights and direction to CS and identity investigations in a multilingual setting. Thus, in view of the importance of hybrid identities in general, and the dearth of research on hybrid identities in the Pakistani context in particular, the current study aims to unpack the link between CS and identity. The main question that is addressed in this paper is related to a group of speakers comprising lecturers and students from an English department at a university in Pakistan: How do the lecturers and students at a university in Pakistan construct their identities through their code-switching practices? 


\section{HYBRID AND BICULTURAL IDENTITIES}

New developments particularly in the field of communication and information technology, have strongly affected our way of thinking and living, and have also led to the creation of multicultural and multilingual societies and spaces. For example, O'Sullivan, Hunt and Lippert (2004) showed how new technological development can lead to the creation of computer mediated communication systems through which individuals can foster psychological closeness and develop relationships. These new advancements have changed people's conceptions of self and others, which are reflected in their interactive practices and behaviours. Language users not only try to link themselves to their local or national communities, but at the same time desire to cross the physical and geographical borders and aspire to join other communities and act globally (Arnett, 2002). The same global aspirations were found in the identity construction of Malaysian men as reported by Nur Syuhada Mohd Radzi, Bahiyah Dato' Haji Abdul Hamid and Kesumawati Abu Bakar (2018). They showed that the identity construction of Malaysian men in relation to masculinity is strongly influenced by global forces and trends.

These aspirations and thinking have resulted in the emergence of hybrid and bicultural identities. Although hybrid and bicultural identities are generally used as alternative terms, there are conceptual differences between the two. The term 'hybrid' in this context refers to the integration of two different types of identities into a single whole; while in bicultural identities, both types of identities are retained and maintained separately side by side (Almutairi, Raihanah Mohd Mydin \& Ruzy Suliza Hashim, 2019; Lamb, 2009). Arnett (2002, p. 777) defines bicultural identities as something "in which part of...[people's] identity is rooted in their local culture while another part stems from awareness of their relation to the global culture". He further explains that when one form of identity modifies another form, and the resultant is different from both, then that phenomenon is generally known as a hybrid identity. The emergence of the same kind of hybrid identities was reported by Yim and Clément (2019). Their study of Cantonese-English bilinguals in Toronto, Canada, indicated that CS gave rise to mixed emotions. This is because CS can be regarded positively as the speakers' ability to use their heritage language, Cantonese, and also negatively as a sign of poor proficiency in Cantonese. In terms of identity, the use of English-Cantonese CS resulted in speakers being considered as being Westernized or as not belonging to either Chinese or Western culture.

Among another group of Chinese community, a more hybrid cultural connection emerged. In this study, Pue, Ong and Loo (2019) found that youth in the Peranakan Chinese community in Kelantan, in the north-eastern state of Malaysia, were heavily infused with local Malay and Siamese influences. This community tended to use particular language markers, such as 'Assalamualaikum', 'syahdu', and 'munafik' to display familiarity with Malay Muslim culture. Being bilingual with a localized variety of Hokkien, and the Kelantanese variety of Malay is one of the significant markers for a Kelantan Peranakan Chinese identity. When asked, participants reasoned that it was the ability to speak the Kelantan variety of Malay fluently that distinguished them from non-Peranakan Chinese in Kelantan. as well as other Chinese elsewhere in Malaysia.

\section{CODE-SWITCHING AND IDENTITY}

CS and identity have been approached from different theoretical perspectives. Hall and Nilep (2015) published a detailed review on CS and identity where they provided a historical overview of different theoretical paradigms on CS and identity studies. On the basis of theoretical orientations, they classified these studies into four main categories. In the first category, they included studies which explored CS and identity from an ethnographic 
perspective. Here, bidialectal and bilingual practices were viewed as symbolic representations of local and non-local identities. For example, Gumperz's (1982, p. 66) concepts of "we" and "they" codes were correlated with certain prior identity positions such as solidarity, intimacy, formality and authority shared by the entire speech community. Likewise, Myers-Scotton's (1993, p. 131) concepts of "marked" and "unmarked" choices were also used in the local communities for certain presupposed functions and situations. However, all these concepts have been criticised for their prior assumed correlation between the linguistic forms and their functions ahead of its use.

The second tradition, which began in the 1980s, focused on nation-state identities. In this tradition, a symbiotic relationship between language and social and national ideologies was also assumed. Interactive practices were seen as a reflection and production of social and political relations and associations. Studies using this approach assumed language choices as being ideologically and politically motivated reproducing social hierarchies. In short, the perception of a speaker about self and other are shaped and moulded by political, economic and social considerations (Woolard, 1985). The third tradition emerged in the 1990s and challenged the static functional approach by focussing on CS and identity from an interactional discursive perspective. The supporters of this approach opposed the prior functional categorization of CS and identity by emphasizing a dynamic construction of identities through the interactive practices of the speakers. CS was considered as a resource for the construction of different interethnic and multicultural identities (Martin, 2003). The third tradition is linked with the fourth tradition, which focuses on hybrid identities, and emerged due to the current surge of globalisation. These studies crossed ethnic and national borders considering them to be elusive since people are no longer restricted to the confines of their regional and national boundaries. Given the complexities of current day multilingual contexts, it is not surprising that ethnic and national classification of identities are challenged, and languages are regarded as being fluid and dynamic rather than entities that can be classified into separate and discrete categories (Casas, 2008; Kebede, 2017; Rosendal, 2017).

In view of this more dynamic approach to identity, the current study is based on the framework of Bucholtz and Hall $(2005,2008)$. Bucholtz and Hall $(2005$, p. 607) posit "that identity is emergent in discourse and does not precede it" and thus, "we are able to locate identity as an intersubjectivity achieved social and cultural phenomenon". The framework of Bucholtz and Hall (2005) is an integration of insights drawn from different areas. They mainly focussed on the micro and macro categorisation of identities. The micro category refers to identity positions or roles and attributes resulting from the interactional and immediate context of a situation or interactive episode. For example, the lack of hesitation, breaks and the diverse bidirectional alternation can be considered as micro attributes. Similarly, someone can perform the temporary role in a particular context, all these are subsumed under the micro category. As Bucholtz and Hall (2005, p. 591) explain "at the most basic level, identity emerges in discourse through the temporary roles and orientations assumed by participants, such as evaluator, joke teller, or engaged listener". The broader socio-cultural factors or ideologies (e.g., class and gender) are labelled as macro. Bucholtz and Hall (2008) argued that in addition to micro-macro perspectives, there also arises the need for a third level which could mediate and support the previous two levels. They refer to this as a stance or the participant's intention for using a particular linguistic structure in a particular sense in a specific context.

However, in this study, the local and interactional categories of Bucholtz and Hall (2008) have been merged into the micro category, while the social category remains in the macro category. The reason for merging the local and interactional layers is that there exist overlaps and fine differences between the two, hence blurring the categories. This is why many studies (e.g., Casas, 2008; Lamb, 2009; Rosendal, 2017) have used two major categories, the micro and macro. In this way, the micro world of interaction refers to the broader world of the 
speakers. For instance, Lin (2017) investigated identity construction in the interactive practices of the local Taiwanese and international university students in Taiwan. The findings, which were derived from interviews, showed that the students discursively constructed their linguistic and cultural identities. The word linguistic is used for micro identities, and cultural for macro identities of the students. This study highlights the point that both groups of students are influenced by their socio-cultural backgrounds in their identity constructions. The study further suggests that while investigating identities, such as in the current context, one should also take into consideration both, the local linguistic and the broader cultural dimensions. Likewise, similar findings emerged in another study that examined CS and identity construction among Ngoni native speakers in Swahili-Ngoni, Tanzania (Rosendal, 2017). The study aimed to show that the symbolic values of Swahili and Ngoni are negotiated in the social actions and interactive practices of the speakers. The findings revealed that despite the fact that Ngoni is their native language, which symbolically represents their strong ethnic identities, the speakers frequently code-switched between Swahili and Ngoni in a dynamic manner. This could be ascribed to particular historical, ideological and socio-cultural factors. In this context, the diverse CS practices of the speakers are indicative of the shift from a single Ngoni identity to a Ngoni-Swahili hybrid identity, reflecting the socio-political dimension of their societal structures.

\section{METHODOLOGY}

\section{LOCATION AND PARTICIPANTS}

The current study was conducted in a public sector university in Pakistan. The university is located in Mardan, one of the main cities in Khyber Pakhtunkhwa, a province in Pakistan. Initially, one university each from three major cities in the Khyber Pakhtunkhwa province was selected for the study. However, security conditions at the point of data collection deteriorated in the wake of attacks on soft targets which included educational institutions in the area. In such circumstances, it was not possible to get access to the other institutions for research purposes. Thus, the study was restricted to one university in the area, to which the first author had access. The Pashtuns are the dominant ethnic group in Khyber Pakhtunkhwa. Hence, Pashto is the native language of the majority of the people here. In addition to Pashto, the national language, Urdu and English, which is the main medium of instruction in higher education are used. It should be noted that despite the fact that Urdu is the national language, lecturers and students at universities in this region quite frequently code-switch more between English and Pashto. Before proceeding with the data collection process, all ethical formalities, including obtaining consent from the participants, were fulfilled. A total of 26 participants including four lecturers and 22 undergraduate students from a total of 11 lecturers and 40 final year students were purposively selected from the English Department where they major in English Literature. These participants were selected based on their native language being Pashto. Only those from the English Department were selected as this meant that they were more likely to be more fluent in English, and therefore, use English in their interactions with each other compared to students and staff from other departments. The final year students were selected as they tended to be more confident providing their feedback on their interactional practices. Both lecturers and students were selected as this study aimed to examine the interactions among these two main groups of people in an academic setting. The age range of the lecturers was between 25 to 45 years old, while the age range of the undergraduate students was between 18 to 25 years old. For the purpose of reporting, the participants are anonymised. The students were coded as S1 to S22, and the lecturers, L1 to L4. The participants comprised 11 male and 11 female students, and 2 male and 2 female lecturers. 


\section{INTERACTIONS}

A total of nine hours and 24 minutes of lecturers' and students' interactions were video recorded. The recorded interactions are shown in Table 1. Each of the four lecturers was recorded conducting their class, and all 22 students were present in each of the four lectures. In other words, each recorded lecture comprised one of the four lecturers and all 22 students. After the lecture was over, the students stayed back in class to discuss the lecture and waited for their next lecture. The students were recorded during this period after four of the previously mentioned lectures. The four lecturers were recorded in the staff or faculty room talking to each other on four occasions.

TABLE 1. Recordings of the interactions

\begin{tabular}{ccc}
\hline Contexts & Total duration & Locations \\
\hline Interactions during lectures & 3 hours 7 mins & Classroom \\
Students' interactions after lectures & 3 hours 20 mins & Classroom \\
Interactions amongst the four lecturers & 2 hours 57 mins & $\begin{array}{c}\text { Faculty room } \\
\text { (staff room) }\end{array}$ \\
\hline
\end{tabular}

Whilst the recordings were taking place for all three contexts in Table 1, the interactions were also observed by the first author, who did not participate in the interactions.

\section{SEMI-STRUCTURED INTERVIEWS}

Keeping in view the nature of the current study and the importance and utility of interviews in the current context, a series of semi-structured interviews was also conducted. These interviews were conducted after the recordings of the interactions and were guided by six main questions designed for a larger study, under which the current study is subsumed. The first question was related to the number of languages they speak. The second sought to elicit the perceptions of the speakers about language alternations, while the third question asked them about their motivations and reasons for CS. The fourth was related to the pedagogic uses of CS, and the fifth to the types of CS. The sixth question was aimed at obtaining the participants' insights on $\mathrm{CS}$, language, culture and identity. The two main questions that were related to the current study are the third ('In your opinion why do you change language or use different languages in the classroom?'), and the final one ('How do you view the relation between changing language/integration of languages and culture?'). It should be noted here that being a semistructured interview, several other subsidiary questions falling within the realm of the two main questions in the current context were also asked during the course of the interviews. The interviews focussed on the social status and identity orientations of the speakers at this point.

For an in-depth feedback from the participants, they were briefed about the purpose of the current study. All the questions were explained to them in both English and Pashto. The 22 participants were given the freedom to express their views, and to use any language of their choice, which could be Pashto, Urdu and English. However, they used mainly English and Pashto. The interviewer essentially spoke as he would do naturally with the participants, and this meant that he also code-switched as this is a normal occurrence in this context. Whilst this may have influenced the language used by the participants during the interview, the interviews were not the primary source of data. The interviews were used to obtain feedback on their language use, and in particular their language use in the recorded interactions. The interview duration for all the participants was 10.33 minutes. The interviews were carried out in a room on campus for the students and for the lecturers, the interviews were conducted in their individual offices. The interviews were videotaped with their consent. The semi-structured 
interviews helped to obtain feedback from the participants on their own interactive practices. The data of the interviews were thematically analysed guided by Braun and Clark (2006). The findings from these interviews were also used to triangulate the findings of the recordings of the interactive practices conducted earlier.

\section{TRANSCRIPTION CONVENTIONS}

After the completion of the data collection process, the recording of the interactive practices of the lecturers and students were orthographically transcribed. The transcriptions were guided by the transcription conventions outlined by Barnard and McLellan (2013). Similar to Shah, Pillai and Sinayah (2019), bold letters were used for Pashto utterances, while italics were used for English. Urdu was indicated in bold capital letters. A translation of the Pashto and Urdu utterances are provided in parenthesis. The following is an example of a transcribed extract:

search it on internet it's very interesting story nu chi kala warta (when he was given) pounds aow har sa (and everything) gold warkrul da chi wapus raghly nu da (when he returned) gold taaj ye warla (the golden crown) prepare kray wu da (was prepared) thirty pounds after ninety days TAJ POSHI MAQARAR HOAI (coronation was scheduled) in English we called it coronation AP KO YAD KHA (do you remember?)

[Search for it on the Internet. It's a very interesting story. When he was given pounds, gold and everything, after some time, he returned with the golden crown. The crown was prepared with thirty pounds. After ninety days, the coronation was scheduled. In English we call it 'coronation'. Do you remember?)]

(Shah, Pillai \& Sinayah, 2019)

\section{ANALYTICAL FRAMEWORK}

The transcribed data was coded by first, annotating the switching positions in the transcription. Then on the basis of position and length of the utterance, three different types of CS (Intersentential, Intra-sentential and Tag CS) were identified and labelled as Inter CS, Intra CS and Tag CS. In the categorization of CS, Poplack's (1980) three-pronged scheme of CS was used. This helped in the identification of where CS was taking place before the next level of analysis was conducted as part of the larger study on identity construction. However, CS types will not be discussed in this paper as the focus is on the construction of identity via CS practices.

In the following extract, for instance, the speaker begins in English and utters a complete sentence in the same language. Then he turns to Pashto and delivers another sentence in English. Since code-switching occurs at the sentence level here, it was labelled as Inter CS.

our results dishearten us munga dir mehnat kary wu khu mung ta numbary kamay milao shave (We have worked hard but could not achieve good grades) I am not satisfied

[Our results disappointed us. We have worked hard but could not achieve good grades. I am not satisfied.]

In Intra CS, code-switching occurs within a sentence. In the case of Tag CS, a phrase is attached to a sentence which is otherwise entirely in another language.

Likewise, for micro and macro reasons of CS, the switching points were analysed and then, they were categorized based on the function and purpose the speakers code-switched within a specific context (Gulzar, 2010). In the macro categorization of micro reasons, specifically the social context, the background and views of the participants were taken into considerations. In this way, the micro reasons were found to be linked with the socio-cultural, 
socio-psychological and communicative aspects of the participants who implicitly remain involved in their selections of language choices.

The transcribed data were subsequently examined from the perspective of identity orientations. As explained previously in this paper, the dynamic perspective takes identity as not something given, but structures and restructures by the speakers through their interactive practices in a dynamic and emergent manner. In other words, identity is not restricted to certain predefined features or concepts, but is multiple and an ongoing process subject to continuous change. The analysis of CS and identity is based on an adapted version of the framework by Bucholtz and Hall $(2005,2008)$. Here, the local and interactional categories of Bucholtz and Hall (2008) are merged into the micro category, while the social category remains in the macro category. To reiterate, the micro identities are those from the immediate context of interactions, while macro identities are the broader socio-cultural identities. Three main macro categories, ethnic, elite class and bilingual hybrid identities were categorised, which were then elaborated accordingly. In the case of the ethnic and elite identity orientations, the participants may have seemed to deliberately or consciously switch to Pashto or English. This was determined based on the context of the utterance and the flow of the speech where the speakers were found making breaks, pauses, appearing that they were trying to switch to another language consciously/deliberately. In the case of hybrid identity orientations, the participants codeswitch unconsciously as indicated by the context, lack of hesitations, breaks and diverse nature of alternations. The same was confirmed by the participants in their interviews. For the purpose of this paper, the focus will be on this part of the analysis.

The extract in Table 2 illustrates how the transcribed data were coded. Here a lecturer discusses with his colleagues, the responsibilities of parents in bringing up and educating their children. Initially, he begins in English and talks about parents in general. He explains that they should take care of their children. They should give them proper attention and time. When he turns to his home and children, he switches from English to Pashto. The speaker's change of language is accompanied by a change of position from expert/formal to father/informal, and was consequently labelled as a sign of ethnic orientation and placed in the socio-cultural category (Bucholtz \& Hall, 2005, 2008).

TABLE 2. Coding of transcribed data

\begin{tabular}{llll}
\hline \multicolumn{1}{c}{ Extract } & Type of CS & Reasons for CS & $\begin{array}{c}\text { Identity } \\
\text { Orientation }\end{array}$ \\
\hline $\begin{array}{l}\text { One should take care of children and should give } \\
\text { them time (...) za khu chi laarshum tool wakht me } \\
\text { hapalu bacho sara ve (When I return home (.), I } \\
\text { spend most of the time with my children) kala- } \\
\text { kalayaw sara masroof yum kala bul sara (I remain } \\
\text { busy either with one or the other) children have right } \\
\text { over parents }\end{array}$ & Inter CS & $\begin{array}{c}\text { Attachment with } \\
\text { native language/ } \\
\text { personal matters } \\
\text { Socio-cultural }\end{array}$ & $\begin{array}{c}\text { Ethnic identity } \\
\text { orientations }\end{array}$ \\
$\begin{array}{l}\text { [One should take care of one's children and should } \\
\text { spend time with them. When I return home, I spend } \\
\text { most of the time with my children. I am busy with } \\
\text { one or the other of them. Children have the right to } \\
\text { be with their parents.] }\end{array}$ & \\
\hline
\end{tabular}

An outline of the process of coding and data analysis of the interactive data is shown in Figure 1. 


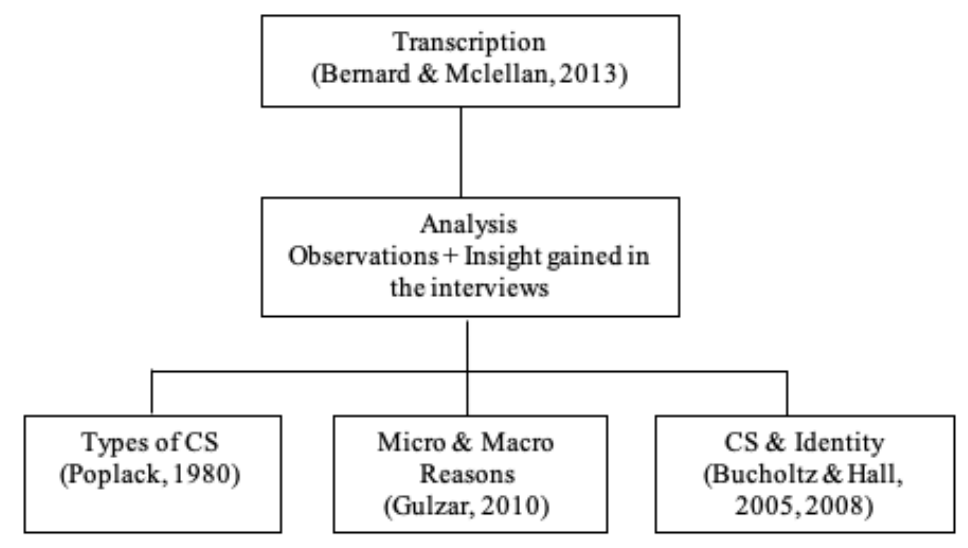

FIGURE 1. Process of transcription, coding and data analysis

In order to validate the categorisation and coding of the current study, a sample transcript from one recording was given to two other researchers who work in the area of Sociolinguistics. They were requested to codify and categorise the sample data in the light of the research questions. They codified it for CS type, reasons for CS and identity orientations. They generally agreed with the overall categorisation and coding of the data. Minor instances of disagreements were discussed and reviewed. They agreed to $95 \%$ of the categorisations and coding. They also suggested elaborating on the CS for social status and solidarity. Revisions were made based on the discussion and suggestions.

Further, the interviews with the participants elicited feedback on their interactive practices, where the categorisations and interpretations of all the transcripts were also shared with the participants. Because the interactive data and interviews are guided by the same research questions, the findings of the interactive practices were validated by the participants' own explanations and comments. The interview questions were asked whilst also sharing transcripts of the participants' interactions.

\section{FINDINGS AND DISCUSSION}

As mentioned in the previous section, the main focus is on the analysis pertaining to the micro and macro identity orientations of the participants. The micro reasons, such as unconscious CS, CS for emphasis and clarity, social status, solidarity, explanation, conclusive remarks, translation, expression of emotions, quotation and topic change, led to the macro socio-cultural, socio-psychological and communicative factors, which implicitly guided the participants in their language choices. Table 3 provides a summary of the findings related to micro and macro identities. The table shows that in the first two cases where the CS remains unidirectional (English to Pashto and Pashto to English), the participants deliberately or consciously try to code-switch for the purpose of projecting their ethnic and elite class identity orientations, while in the last case, CS remains bi-directional and the participants unconsciously engage in CS to project their hybrid identity orientations. 
TABLE 3. Macro and micro identities

\begin{tabular}{|c|c|c|}
\hline Language & Micro attributes or identities & Macro identities \\
\hline English to Pashto & $\begin{array}{c}\text { Informal, light mode (friend, joker/humorous) } \\
\text { Personal family matters (daughter, sister, father, elder, } \\
\text { husband) } \\
\text { Past (narrator) } \\
\text { cultural matters, community membership (member of } \\
\text { community) }\end{array}$ & $\begin{array}{l}\text { Ethnic identity /social- } \\
\text { cultural identity }\end{array}$ \\
\hline Pashto to English & $\begin{array}{l}\text { To show, happiness, anger, grief (emotional) } \\
\text { Formal, to appear educated, to appear learned person } \\
\text { (teacher, student, scholar, critic) } \\
\text { Assuming upper class membership (arrogant, } \\
\text { indifferent, leader, open, unbiased) }\end{array}$ & $\begin{array}{l}\text { Elite class identity / } \\
\text { socio-cultural } \\
\text { /socio-psychological }\end{array}$ \\
\hline Bi-directional & $\begin{array}{l}\text { Unconscious or habitual (mixed) Diverse and } \\
\text { integrated lacking, breaks and pauses in their } \\
\text { orientations }\end{array}$ & $\begin{array}{l}\text { Hybrid bilingual identity/ } \\
\text { socio-cultural } \\
\text { considerations }\end{array}$ \\
\hline
\end{tabular}

In the following section, micro and macro manifestations of identity will be discussed with extracts from the interactions and feedback obtained from the interviews and observations. Extracts labelled as ID refer to data from the interactions, and those labelled as INT refers to data from the interviews (see Appendix for the transcription conventions).

In general, the participants were found to use mainly English and Pashto with hardly any Urdu. This can be seen in the following extract from the recorded lecture. In Extract 1, L3 discusses the relationship between the environment and children's health. He begins his argument in English, and then switches to Pashto as he gives personal examples (see Appendix for transcription conventions). The use of English for more formal topics, and Pashto for more informal personal topics can be linked to the social significance of the two languages. The use of Pashto for personal matters can be said to show the speaker's attachment with his culture and community. It can also be linked to the different identities of the speaker: lecturer (formal, English) and father (personal, informal). The speaker uses Pashto when acting as family member, thus showing an ethnic identity orientation. English, on the other hand, is used to appear formal which suggests an elite class identity orientation.

Extract 1: ID

L3. The child get used to this environment and then it has no effect on them. Habara sadasy da kana chi zamunga hum sa cousin di sa pa kale sa pa Peshawar ke osegi aow sa Australia ke di alta osegi (I have cousins. Some of them live in Peshawar and the others in Australia.). Nu chi dalta rashi bemar shi (When they come back here to the village, they usually develop a cold or a fever). Khu chi kom mashuman pa di naalu ki lvi shi nu da di immunity develop shi aow pa haghvi asar na kavi (But my cousins who live in the village are used to the village environment and this has no effect on them). So, this is natural and happens everywhere.

[The child gets used to this environment and then it has no effect on them. I have cousins. Some of them live in Peshawar and the others in Australia. When they come back here to the village, they usually develop a cold or a fever. But my cousins who live in the village are used to the village environment and this has no effect on them. So, this is natural and happens everywhere.]

However, in another extract from the recorded lecture, the separation between a formal lecturer-student relationship appears to be superseded by a, perhaps, more natural and expected phenomenon among bilinguals sharing the same languages. Here, the speaker moves in and out of Pashto and English rather seamlessly. This is shown by the flow of speech, rapid and diverse 
alternation between English and Pashto, having no pause or break. Here, in Extract 2, L1 is talking to the students about Shakespeare's Julius Caesar, and explaining quotes from the play:

Extract 2: ID

L1. Laka ambition dir da sakht seez na juregy ambition (Ambition is made of hard stuff) aow za khu yaw boda dagha da (I am an old man) Lady Anthony wept with Caesarwept with that lady hagha pa jara shavay wu da khu di ki ambition (He wept and it was his ambition). Hagha khkari aow taso ta khu ye bala shay dagha aow (He was not what he seemed to be). Thus, we presented him thrice the crown which he thrice refused dree zul warta mung crown warkao hagha dree zul oghurzao (We offered him crown thrice but he refused). Matlub da chi diry qissay warta okry kana (In short, he narrated many stories to them).

[Ambition is made of sterner stuff. I am an old man. Anthony's wife wept with Caesar. He wept with that lady. He wept and it was his ambition. He was not what he seemed to be. Thus, we presented him with the crown three times and he refused each time. In short, he narrated many stories.]

The weaving in and out of the two languages can be related to the social background of the lecturers and students. They are brought up in a social setting where they have been exposed to and use Pashto and English frequently over a period of time, especially in more formal contexts such as in education. This has led to code-switching between Pashto and English being commonly used in an academic setting. In such a situation and context, the emergence of unconscious CS appears to be spontaneous (see Shah, Pillai \&Sinayah, 2019) as there exists no pause, break or hesitation. Rather the speaker goes back and forth between the two languages in a fluid manner. These micro attributes are indicative of the speaker's hybrid bilingual identity orientation. This can also be evidenced from the next extract.

Extract 3 is the contribution from participant S7 taken from one of the post-lecture interactions among the students. However, in this extract, there also appears to be the element of emotions involved in the choice of language use. The interaction revolves around the unexpected Cumulative Grade Point Average (CGPA) that they obtained for the previous semester. S7 expresses his frustrations about the previous semester's results which he felt were what any average student could obtain. He first starts in English by positioning himself as a complainant then switches mainly to Pashto to express his dissatisfaction. Hence, Pashto appears to be used to express strong feelings. Here, it can be clearly observed that the speaker code-switched between the two languages in a dynamic manner with no break and pause. The context and flow of speech show the hybrid identity orientation of the speaker, which could be linked to his socialisation in a multilingual environment. This is also endorsed by the speaker in the subsequent extract.

Extract 3: ID

S7. Because we have study quite a lot mung dir ziat study karay wa tareeqa eighteen hour sixteen hours mung study kawala (Because we studied a lot up to sixteen eighteen hours) chi senga mung results raghaly nu da haghay na baad zamung zra maat shu (But the results greatly disappointed us and broke our hearts) and da haghayna baad hagha shanty hagha shanty results mungta milao na shu (and the results were contrary to our expectations) zaka chi three gpa yaw normal kus nun saba achieve kavi hagha three gpa $\mathbf{v}$ aow mung I pa haghay $\mathbf{k}$ three gpa rakary wa (Because an average person obtains a 3.0 CGPA easily and we were given just a 3.0 CGPA) so that's my view.

[Because we studied a lot up to sixteen eighteen hours but the results greatly disappointed us and broke our hearts. And the results were contrary to our expectation because an average person obtains a 3.0 CGPA easily and we were given just a 3.0 CGPA. So that's my view.] 
When asked about his use of CS in the recordings during the interview with him, S7 gives a very comprehensive reply as shown in Extract 4. In the first line, the speaker in Extract 4 classifies CS into two: unconscious and conscious. He elaborates that at this point, he was not aware of his CS. He then talks about the nature of habitual CS. He then goes on to explain that in a multilingual setting such as Pakistan, CS is a commonly observed phenomenon and an inevitable practice. This point can be observed in the previous extracts as well.

\section{Extract 4: INT}

S7. Da code-switching dwa main types di (There are two main types of code-switching). First ziat tur codes-witching mung unconsciously kao (mostly we code-switch unconsciously). Laka da pas example chi senga warkary shavay da mataos da pata natural da (The extract mentioned is one such example of unconscious CS and I don't know why I have mixed Pashto and English). Aow da di waja zamung background da (One of the main reasons is our multilingual backgrounds) aowajeebahabra da $\mathbf{k}$ educated veaow $\mathbf{k}$ uneducated khu English words ba use kavi (Surprising, formally educated and uneducated people both used to code-switch). Zaka chi halq pa $T V$ amgreezy programona gori, pa internet gori waghaira (One of the main reasons for this situation can be their exposure to English movies, dramas and programmes on television, accessed through the internet). Da English culture zamung da culture hissa jura shve da. k za owim chi zamung culture Anglicized shava da nu ghalata ba na ve (It looks like that our local culture has been Anglicised). Secondly, kala na kala mung qasda hum code-switching kao (Secondly, we use code-switching consciously at times too).

[There are two main types of code-switching. First we mostly code-switch unconsciously. The extract mentioned is one such example of unconscious CS and I don't know why I have mixed Pashto and English. One of the main reasons is our multilingual backgrounds. Surprising, formally educated and uneducated people both code-switch. One of the main reasons for this situation can be their exposure to English movies, dramas and programmes on television, accessed through the internet. It looks like that our local culture has been Anglicised. Secondly, we use code-switching consciously at times too.]

The speaker in Extract 4 continues to say that English has changed the shape of the local culture and given birth to a new culture; a blend of English and local. He used the word 'Anglicized' to highlight the cultural change (from local to hybrid). Finally, the speaker elucidates that the change in the culture is brought about by the exposure to English culture, made possible by their direct access to television (English channels), movies, internet, and direct contact with English native speakers. This change is reflected in the interactive practices of the participants, which can be observed in the emergence of unconscious CS indicative of the hybrid identity of the speakers.

Similar points were brought up by L3 and S14 during their interview sessions. L3 was asked to comment on her use of CS, and she provided an in-depth reply as shown in Extract 5:

Extract 5: INT

L3. I don't know, za pe na yum pohe shave (I code-switch unconsciously). It happened with me unconsciously. Sometimes I am not aware of my languages even at home with my brothers, sisters, parents. Aow bahar hum friend sara aksar dasy kegi (Even when I go out with my friends, we quite often code-switch). Da os zamung adat jur shavay, har yaw kus dasy kavi (Now we habitually use code-switching and it happens with everybody). D di pa waja zamung pakhtune culture hums dir change shu (This has changed our Pashtun culture). Now we commonly observe that our culture is modernised.

[I don't know, I code-switch unconsciously. It happens with me unconsciously. Sometimes I am not aware of my languages even at home with my brothers, sisters, parents. Even when I go out with my friends, we quite often code-switch. Now we habitually use code-switching and it happens with everybody. This has changed our Pashtun culture. Now we commonly observe that our culture is modernised.] 
L3 feels that CS is not restricted to a particular setting or place as people code-switched at home, outside with friends and almost everywhere. She also feels that in a multilingual environment, CS is a habitual phenomenon. She further explains that CS symbolises modernisation of their native Pashtun culture. Her statement reveals the impact of English on the local culture which in the current context is a result of the interactive practices of the speakers via the use of CS. Presumably, this is more prevalent among the more educated population who has English in their repertoire and for whom English consciously or otherwise symbolises a higher social status. At the same time, the use of Pashto reflects speakers' local cultural identity. When speaking in a Pashtun region, it would probably seem odd not to use Pashto at all, and therefore, the use of both Pashto and English is common in particular contexts like academia. At the micro level, the integrated use of Pashto and English could be an unconscious habitual bilingual phenomenon, but looking at it from a macro lens reveals the social structure and socio-cultural considerations of Pakistani community wherein these two languages are embedded. This blend of local and global influences is not just evident in their speech but can be seen in their attire, food and way of life. In other words, the unconscious blend of English and Pashto can be linked to the emergence of hybrid identity orientations guided by socio-cultural considerations.

S14 in Extract 6 also talks about her CS practices where she acknowledges that speakers like her code-switch unconsciously because of their bilingual background.

Extract 6: INT

S14. Sometimes I code-switch naturally. I am one hundred percent unaware of what I am doing. Da haghay waja maybe chi mung pa yaw dasy environment ke osegu chi hagha bilingual da (The reason may be that we are brought up and live in a bilingual environment). This might have led to the development of unconscious code-switching and most importantly di English language zamung identity dir affect karay da (English language has strongly affected our identity). We are not the same stuff once we were.

[Sometimes I code-switch naturally. I am one hundred percent unaware of what I am doing. The reason may be that we are brought up and live in a bilingual environment. This might have led to the development of unconscious code-switching and most importantly, the English language has strongly affected our identity. We are not the same as before.]

S14 echoes L3 about the cultural change reflected in the way speakers CS between Pashto and English. She posits that the strong presence of English in their environment has not only led to the development of unconscious CS but has also changed their Pashtun heritage and identity. Perhaps, this points to broader social and global factors that steer the interactive practices of the participants as highlighted by Bucholtz and Hall (2008). If we consider languages not merely as linguistic structures but as embodiments of social, political, national and global ideologies, then the seamless and unconscious CS seen in the extracts can be seen as the amalgamation and integration of two different cultures which lead to the emergence of a type of hybrid identities formed in an academic setting. In other words, the seamless use of CS can be said to symbolically represent the integration of local (Pashto) as well as an academic and global (English) cultural components resulting in a hybrid identity among university students and lecturers.

As shown in the extracts and their feedback in the interviews, the lecturers and students have made a free use of CS in their interactive practices in a habitual and unconscious manner underpinned by socio-cultural and socio-psychological considerations. In most of the cases they code-switched in a dynamic and diverse manner, which at times made it difficult to determine the micro orientations of the speakers. It is as if they have developed a separate language by integrating Pashto and English. The reason for this fluent and dynamic CS may be the socialisation of the speakers in a bi-multilingual environment, which led to the emergence 
of habitual CS. As previously mentioned, the lecturers and students have been brought up in an environment where, on the one hand, they use their native language, and on the other, English is used in different spheres, including as a medium of instruction, in offices, legal and administrative contexts. This appears to have resulted in unconscious CS practices, resulting in the emergence of a hybrid identity where the local culture merges with the global one.

\section{CONCLUSION}

This study set out to address the construction of identity through code-switching practices by a group of lecturers and students. The main characteristic is the seamless and unconscious use of CS between Pashto and English by the participants which was evident in the recorded interactions and verified by the interviews with the participants. The analysis of the interactional and feedback obtained from the interviews established the micro and macro identities of the lecturers and students. This dynamic unconscious CS, where there appears to be no hesitation, break or pause is indicative of the speakers' bilingual hybrid identities. The current data is replete with instances where the lecturers and students without any conscious effort code-switched between English and Pashto in a habitual manner. This reflects the bilingual instinct indexing their bi-multilingual identities and backgrounds. In fact, the speakers were brought up in a multilingual environment, where they were exposed to Pashto and English on a routine basis. This led to the integration of local (Pashto) and global (English) elements in their interactive practices and behaviours, which ultimately resulted in their bilingual hybrid identities. In short, the hybrid identities of the lecturers and students could be attributed to their socialisation in a bi-multilingual environment.

Among the implications of this study is that it may help to mitigate the stigmatized status of CS, which is sometimes regarded negatively as a sign of poor language, particularly in a second language like English. In contrast, this study shows it to be a linguistic resource tied in with expressions of a hybrid identity. The study also contributes to the pool of research on the use of local languages, such as Pashto, within a multilingual context. In the long run, the study may help policymakers to make informed decisions about the practical use of language in multilingual academic settings. However, further research on CS and identity formation in other multilingual settings needs to be carried out to develop our understanding of the relationship between the two, and to unpack its teaching, learning and communicative potential. As they stand, the findings and conclusions are specific to the context and setting of this particular study. Initially, the plan was to conduct the study in three main universities of Khyber Pakhtunkhwa province but security conditions at the point of data collection deteriorated in the wake of attacks on soft targets in the area. In such circumstances, it was not possible to get access to educational institutes for research purposes. Thus, the study was restricted to one university in Pakistan.

\section{REFERENCES}

Almutairi, A., Raihanah Mohd Mydin, \& Ruzy Suliza Hashim (2019). Bicultural identity in Saud Alsanousi's The Bamboo Stalk. GEMA Online ${ }^{\circledR}$ Journal of Language Studies. 19(3), 126-139.

Arnett, J. J. (2002). The psychology of globalization. American Psychologist. 57(10), 774.

Barnard, R. \& McLellan, J. (2013). Code-switching in university English medium classes: Asian perspectives. Bristol: Multilingual Matters.

Braun, V. \& Clark, V. (2006). Using thematic analysis in psychology. Qualitative Research in Psychology. 3(2), 77-101. 
Bucholtz, M. \& Hall, K. (2005). Identity and interaction: A sociocultural linguistic approach. Discourse Studies. 7(4-5), 585-614.

Bucholtz, M. \& Hall, K. (2008). Finding identity: Theory and data. Multilingua: Journal of Cross-cultural and Interlanguage Communication. 27(1-2), 151-163.

Casas, M. P. (2008). Code-switching and identity among island Puerto Rican bilinguals. Unpublished Ph.D thesis, Georgetown University, Washington, USA.

Chang, Y. L. (2014). The construction of language value and legitimacy in aboriginal primary school classrooms in Taiwan. International Journal of Pedagogies and Learning. 9(2), 183-192.

Debose, C. E. (1992). Codeswitching: Black English and Standard English in theAfricanAmerican linguistic repertoire. Journal of Multilingual \& Multicultural Development. 13(1-2), 157-167.

Gulzar, M. A. (2010). Classroom discourse in bilingual context: Effects of codeswitching on language learning in Pakistani TEFL classroom. Unpublished Ph.D thesis, National University of Modern Languages, Islamabad, Pakistan.

Gumperz, J. J. (1982). Discourse Strategies. Cambridge: Cambridge University Press.

Hall, K. \& Nilep, C. (2015). Code-switching, identity, and globalization. In D. T. Heidi, E.Hamilton \& D. Schiffrin, (Eds.). The Handbook of Discourse Analysis ( $2^{\text {nd }}$ ed.) (pp. 597-619). Malden, MA: Wiley-Blackwell.

Kebede, K. (2017). Twice-hyphenated: Transnational identity among second-generation Ethiopian-American professionals in Washington, DC, metropolitan area. African and Black Diaspora: An International Journal. 10(3), 1-17.

Lamb, M. (2009). Situating the L2 self: Two Indonesian school learners of English. In Z. Dornyei \& E. Ushioda, (Eds.).Motivation, Language Identity and the L2 Self (pp. 229247). Bristol: Multilingual Matters.

Mabule, D. R. (2015). What is this? Is it code switching, code mixing or language alternating? Journal of Educational and Social Research. 5(1), 339-349.

Mahboob, A. (2017). English medium instruction in higher education in Pakistan: Policies, perceptions, problems, and possibilities. In B. Fenton-Smith, P. Humphreys \& I. Walkinshaw, (Eds.).English Medium Instruction in Higher Education in Asia-Pacific: From Policy to Pedagogy (pp. 71-92). Cham: Springer International Publishing.

Manan, S. A., David, M. K., Dumanig, F. P., \&Channa, L. A. (2017). The glocalization of English in the Pakistan linguistic landscape. World Englishes. 36(4), 645-665.

Manan, S. A., Dumanig, F. P., \& David, M. K. (2017). The English-medium fever in Pakistan: Analyzing policy, perceptions and practices through additive bi/multilingual education lens. International Journal of Bilingual Education and Bilingualism. 20(6), 736-752.

Martin, P. W. (2003). Bilingual encounters in the classroom. In J. M. Dewale, A. Housen \& Li Wei, (Eds.).Bilingualism: Beyond Basic Principles (pp. 67-87). Clevedon: Multilingual Matters.

Myers-Scotton, C. (1993). Social Motivations for Codeswitching: Evidence from Africa. Oxford: Clarendon Press.

Norton, B. (2000). Identity and Language Learning: Gender, Ethnicity and Educational Change. Essex: Pearson Education Limited.

Nur Syuhada Mohd Radzi, Bahiyah Dato' Haji Abdul Hamid, \& Kesumawati Abu Bakar (2018). Discursive construction of modern masculine identities in contemporary Malaysia. GEMA Online ${ }^{\circledR}$ Journal of Language Studies. 18(3), 35-56.

O'Sullivan, P. B., Hunt, S. K., \& Lippert, L. R. (2004). Mediated immediacy: A language of affiliation in a technological age. Journal of Language and Social Psychology. 23(4), 464-490. 
Poplack, S. (1980). Sometimes I'll start a sentence in Spanish y terminoen español: Toward a typology of code-switching. Linguistics. 18(7-8), 581-618.

Pue, G. H., Ong, P. L., \& Loo, H. C. (2019). Kelantan Peranakan Chinese language and marker of group identity. GEMA Online ${ }^{\circledR}$ Journal of Language Studies. 19(2), 33-51.

Rosendal, T. (2017). Identity construction and norms of practice among bilingual Ngoni in rural Tanzania. Language Matters. 48(2), 3-24.

Saraswati, R., \& Octavita, R. A. I. (2016). A study of English code-switching in Indonesian Teen Magazine. Deiksis. 8(01), 39-47

Shah, M., Pillai, S., \& Sinayah, M. (2019). Translanguaging in an academic setting. Lingua. $225,16-31$.

Smirnova, A. \&Iliev, R. (2016). Political and linguistic identities in an ethnic conflict. Journal of Language and Social Psychology. 36(2), 211-225.

Woolard, K. A. (1985). Language variation and cultural hegemony: Toward an integration of sociolinguistic and social theory. American Ethnologist. 12(4), 738-748.

Yim, O. \& Clément, R. (2019). "You're a Juksing": Examining Cantonese-English codeswitching as an index of identity. Journal of Language and Social Psychology. 38(4), 479-495. 


\section{APPENDIX}

\section{TRANSCRIPTION CONVENTIONS}

\begin{tabular}{cc}
\hline Convention & Explanation \\
\hline $\boldsymbol{(})$. & Rising intonation \\
$(\ldots)$ & Short pause \\
Long pause \\
$=$ & Underlining use for emphasis \\
$:$ & Latching used for no gap between turns \\
CAPITAL BOLD & Stretching of sounds \\
Bold & Urdu \\
Italics & Pashto \\
$($ ) & English \\
// & Translation of the words/ for noise / laughter/ unclear speech \\
L & Slashes indicate overlap \\
S & Lecturer \\
SS & Student \\
ID & Students in group \\
INT & Used for extracts taken from interactive data \\
& Used for extracts taken from data of the interviews \\
\hline
\end{tabular}

\section{ABOUT THE AUTHORS}

Mujahid Shah is an assistant professor at the Department of English, Faculty of Arts \& Humanities, Abdul Wali Khan University, Pakistan. His main area of interest is sociolinguistics and applied linguistics, specifically sociolinguistic investigations of bi-multilingual investigations, bi-multilingual practices and identity constructions.

Stefanie Pillai is a professor at the Faculty of Languages \& Linguistics, Universiti Malaya. Her research areas include the acoustic features of spoken languages, language choice and use, as well as, language documentation and revitalisation.

Malarvizhi Sinayah is a senior lecturer at the Department of Malaysian Languages and Applied Linguistics, Faculty of Languages \& Linguistics, Universiti Malaya. Her research interests lie in the areas of Sociolinguistics and Discourse Analysis in general, and Tamil linguistics and the teaching of Tamil language and literature in particular. 